\title{
Anticorrosive waterborne epoxy (EP) coatings based on sodium tripolyphosphate-pillared layered double hydroxides (STPP-LDHs) \\ DOI:
}

10.1016/j.porgcoat.2019.04.055

\section{Document Version \\ Accepted author manuscript}

Link to publication record in Manchester Research Explorer

Citation for published version (APA):

Wang, N., Gao, H., Zhang, J., Li, L., Fan, X., \& Diao, X. (2019). Anticorrosive waterborne epoxy (EP) coatings based on sodium tripolyphosphate-pillared layered double hydroxides (STPP-LDHs). Progress in Organic Coatings, 135, 74-81. https://doi.org/10.1016/j.porgcoat.2019.04.055

\section{Published in:}

Progress in Organic Coatings

\section{Citing this paper}

Please note that where the full-text provided on Manchester Research Explorer is the Author Accepted Manuscript or Proof version this may differ from the final Published version. If citing, it is advised that you check and use the publisher's definitive version.

\section{General rights}

Copyright and moral rights for the publications made accessible in the Research Explorer are retained by the authors and/or other copyright owners and it is a condition of accessing publications that users recognise and abide by the legal requirements associated with these rights.

\section{Takedown policy}

If you believe that this document breaches copyright please refer to the University of Manchester's Takedown Procedures [http://man.ac.uk/04Y6Bo] or contact uml.scholarlycommunications@manchester.ac.uk providing relevant details, so we can investigate your claim.

\section{OPEN ACCESS}




\section{Highlights}

- An anticorrosive coating with a synergistic action of two anticorrosive mechanisms.

- The presence of LDHs layered structure hinders the diffusion of corrosion ions through the coating layer and stops corrosion ions from reaching the metal substrate immediately.

- Triphosphate ions in STPP-LDHs can exchange with corrosive ions such as $\mathrm{Cl}-$ to trap them in the interlayers of LDHs, reducing the amount of ions in the coating layer for metal corrosion. 


\section{Graphical Abstract}

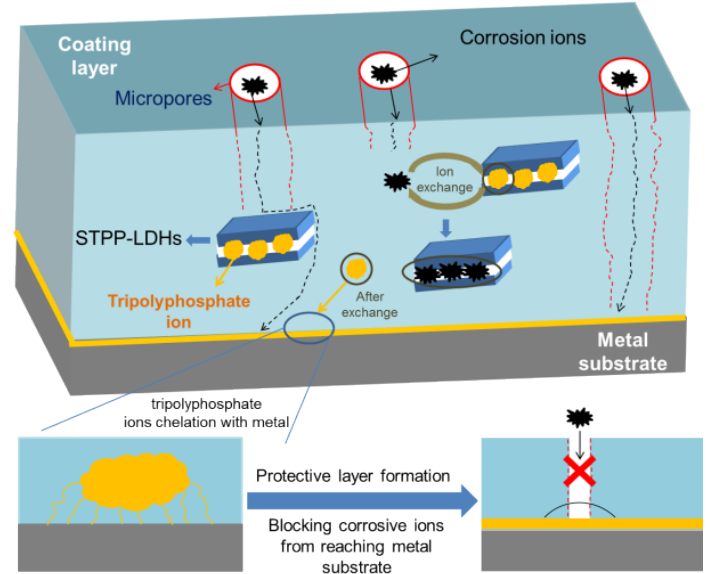

Scheme 1 Schematic diagram of the anti-corrosion mechanism by STPP-LDHs in EP coatings

the anti-corrosion mechanism of STPP-LDHs fillers in the EP coating layer as illustrated in scheme 1. Firstly, the presence of LDHs layered structure hinders the diffusion of corrosion ions through the coating layer and stops corrosion ions from reaching the metal substrate immediately. Secondly, triphosphate ions in STPP-LDHs can exchange with corrosive ions such as $\mathrm{Cl}^{-}$to trap them in the interlayers of LDHs, reducing the amount of ions in the coating layer for metal corrosion. Finally, the released tripolyphosphate ion can act as the chelating agent, initiating the passivation of the metal surface via complexation which makes metals avoid erosion by corrosion ions. 


\section{Anticorrosive waterborne epoxy (EP) coatings based on sodium tripolyphosphate-pillared layered double hydroxides (STPP-LDHs)}

Na Wang ${ }^{12 *}$, Huiying Gao ${ }^{1}$, Jing Zhang ${ }^{1}$, Long Li ${ }^{1}$, Xiaolei Fan ${ }^{3, *}$, and Xinlin Diao ${ }^{1}$

${ }^{1}$ Sino-Spanish Advanced Materials Institute, Shenyang University of Chemical Technology, Shenyang 110142, China

${ }^{2}$ Advanced Manufacturing Institute of Polymer Industry, Shenyang University of Chemical Technology, Shenyang 110142, China

${ }^{3}$ School of Chemical Engineering and Analytical Science, The University of Manchester, Manchester, M13 9PL, United Kingdom

*Corresponding author. Emails: iamwangna@syuct.edu.cn (NW); xiaolei.fan@manchester.ac.uk

\section{ABSTRACT}

Waterborne epoxy (EP) coatings were modified by incorporating sodium tripolyphosphate pillared layered double hydroxides (STPP-LDHs) to improve their anticorrosion ability for steel structures. The structural and morphological properties of STPP-LDHs in reference to LDHs were studied comprehensively using Fourier transform infrared spectroscopy (FTIR), X-ray diffraction (XRD), thermo-gravimetric analysis (TGA) and scanning electron microscopy (SEM), showing the successful intercalation of tripolyphosphate ions within the interlayers of LDHs. The corrosion resistance of the EP surface coatings on the mild carbon steel was assessed by the electrochemical impedance spectroscopy (EIS) and salt spray test, showing the improved anticorrosion performance of the STPP-LDHs modified EP coatings compared to neat EP and LDHs modified EP coating. The results obtained under the controlled corrosive environment (with $\mathrm{NaCl}$ solutions) showed that the specimen coated with EP containing 1.0 wt.\% STPP-LDHs exhibited the optimum anticorrosion performance among other specimens studied. In addition, STPP-LDHs(1.0\%)-EP showed the highest impedance value of EP composite coating of $6.019 \times 10^{8} \Omega \cdot \mathrm{cm}^{2}$, surpassing the state-of-the-art composite EP coatings.

Keywords: Waterborne epoxy (EP) coating; Anticorrosion; Layered double hydroxides (LDHs); Sodium tripolyphosphate (STPP); electrochemical impedance spectroscopy (EIS)

\section{Introduction}

Epoxy (EP) resins, due to their outstanding performance in terms of excellent chemical resistance to many chemical compounds and great adherence to many substrates, are widely used as the corrosion protection for metallic structures/surfaces [1]. Due to the stringent VOCs emission regulation and the requirement of the safer working environment, the use of solvent - based coatings is limited in nowadays [2], leading to the development of waterborne epoxy resin with insignificant environmental impact [3]. Despite the properties above, the application of waterborne epoxy coatings often suffers from their disadvantages such as poor barrier properties, leading to electrochemical corrosion [4,5]. The barrier property, and enhance the corrosion resistance, of waterborne epoxy coatings can be improved by the inclusion of appropriate fillers, such as nanocarbons [6], nanosilicates [7] and organoclay [8].

In our previous work, layered Na-montmorillonite (Na-MMT) [9], mesoporous MCM-41 silica nanoparticles [9,10] and polyethylenimine (PEI) modified meso- $\mathrm{TiO}_{2}$ [4] were employed as the fillers to develop composite epoxy coatings which showed the improved barrier property and corrosion resistance. The results evidenced the effective role of these functional fillers in the coating body to inhibit the corrosion processes. For example, PEI modified meso$\mathrm{TiO}_{2}$ was shown to enhance the interaction with EP to increase the crosslink density of the coating, hindering the transport of corrosive electrolytes through the coating layer [4]. Recently, nanoscale lamellae such as graphene oxide with lamellar structure were explored as well for improving the corrosion resistance of coatings. It was found that the lamellar structure of graphene is able to impede the transfer of electrolytes in the coating body and block the 
micropores, which are formed in the curing process of waterborne epoxy resin by evaporation of water [11].

Layered double hydroxides (LDHs), also known as hydrotalcite-like compounds (HTlc) [12], have the unique lamellar structure (similar to graphene) with high metal dispersion [13]. They are excellent anion exchange materials consisting of stacks of positively charged, mixed-metal hydroxide layers, between which anionic species and solvent molecules are intercalated [13]. LDHs, especially the thermally activated LDHs [14], are excellent anticorrosion materials because their positively charged layered structures can easily intercalate different anions such as chloride $\left(\mathrm{Cl}^{-}\right)$and sulfate $\left(\mathrm{SO}_{4}{ }^{2-}\right)$ which are well-known aggressive corrosive anions. In addition to the ability to hold the corrosive anions in their layered structures, LDHs are also capable of encapsulating and releasing (in the controlled manners) corrosion inhibitors, providing them with supplemental advantage for anticorrosion [15]. There are emerging reports on the corrosion resistance of coatings by using the ion exchange characteristics of hydrotalcite [1623]. For example, the $\mathrm{Zn}_{2} \mathrm{Al} /-\mathrm{V}_{10} \mathrm{O}_{28}{ }^{6-} \mathrm{LDHs}$ are able to release the decavanadate in the amide-cured bisphenol epoxy resin during the ion exchange reaction of capturing chloride [16]. Intercalated species contain inorganic and organic substances, such as: $\mathrm{MoO}_{4}{ }^{2-}$, decavanadate, aniline, benzene derivatives, 2-mercaptobenzothiazolate anions, tripolyphosphates, vanadate 2-benzothiazolythio-succinic acid and 2-hydroxyethyl phosphate [16-23]. Among these, tripolyphosphates (TPPs), especially sodium tripolyphosphate (STPP), are readily available with low toxicity and insignificant environmental effects. Additionally, TPPs are known as efficient corrosion inhibitors owing to their abilities to bind strongly to metal cations as both a bidentate and tridentate chelating agent [24-26]. Both calcium and zinc TPP have shown to chelate with iron ions at anodic sites of steel surface to form the ferric tripolyphosphate insoluble protection layer via the complexation reactions [27].

Hence, in anticorrosion applications, TPPs have been regarded as good candidates to replace the conventional pigments, such as lead or chromium, which are toxic to human and not environmentally friendly [27]. Therefore, the development of LDHs/TPPs composites for anticorrosive applications is rational to benefit from the ion exchange ability of LDHs and the anticorrosion properties of LDHs and TPPs. Previous studies have shown the positive effect of sodium tripolyphosphate (STPP) intercalated hydrotalcite on the flame retardancy of STPP modified coatings $[28,29]$. However, the investigation of TPPs intercalated LDHs composites for anticorrosion applicaions has not yet been conducted.

In this paper, we present the development of tripolyphosphate intercalated hydrotalcite composites as anticorrosion fillers in waterborne epoxy coatings to improve its barrier property, and enhance the corrosion resistance. Sodium tripolyphosphate (STPP) is used to intercalate with magnesia aluminum hydrotalcite [30] (MgAl-LDHs, denoted as LDHs in the following context) via the coprecipitation method to prepare STPP pillared LDHs (i.e. STPPLDHs). Subsequently, STPP-LDHs and LDHs (as the reference filer) and are used as the filler to modify waterborne epoxy resin (by physical blending with different weight percentage of fillers) as anticorrosive coatings for the mild steel substrate. Comparative corrosion tests under the controlled environment with $\mathrm{NaCl}$ solutions are also performed to evaluate corrosion resistance of coatings including neat, LDHs modified and STPP-LDHs modified epoxy resin.

\section{Materials and Methods}

Materials. Sodium tripolyphosphate (analytical reagent, $98 \%, \mathrm{Mw}=367.86$ ) and aluminum nitrate (analytical reagent, 99.0\%, $\mathrm{Mw}=375.13$ ) were purchased from Shanghai Macklin Biochemical Co., Ltd. Magnesium nitrate (analytical reagent, $\mathrm{Mw}=256.41$ ) was supplied by Tianjin Damao Chemical Reagent Tactory. Sodium hydroxide (analytical reagent, $\mathrm{Mw}=40.00)$ was supplied by Tianjin European Bokai Co., Ltd. Waterborne epoxy resin (AR555) and curing agent (anquamine 419) from Air Products and Chemicals, Inc. were used to prepare the filler/paint composites in this work. 
Synthesis of STPP-LDHs. STPP-LDHs composites were prepared using a co-precipitation method. In a typical synthesis, $21.4 \mathrm{mmol} \mathrm{Mg}\left(\mathrm{NO}_{3}\right)_{2} \cdot 6 \mathrm{H}_{2} \mathrm{O}$ and $10.7 \mathrm{mmol} \mathrm{Al}\left(\mathrm{NO}_{3}\right)_{3} \cdot 9 \mathrm{H}_{2} \mathrm{O}$ were dissolved in $45 \mathrm{ml}$ deionized water to form a homogeneous solution (denoted as the solution $\mathrm{A}, \mathrm{Mg}: \mathrm{Al}=2: 1$ ) at ambient temperature. Subsequently, the solution $\mathrm{B}$ was prepared by dissolving $68.3 \mathrm{mmol} \mathrm{NaOH}$ and $12.78 \mathrm{mmol} \mathrm{Na}_{5} \mathrm{P}_{3} \mathrm{O}_{10}$ in $45 \mathrm{ml}$ deionized water at ambient temperature and inert atmosphere (the deionized water was boiled to remove dissolved carbon dioxide and kept at $25{ }^{\circ} \mathrm{C}$ for use). Then, solutions A and B were simultaneously added dropwise to a beaker containing $90 \mathrm{ml}$ deionized water until the $\mathrm{pH}$ value of the final mixture was adjusted to 9 10. The resulting mixture was stirred (at 300 ppm and $70{ }^{\circ} \mathrm{C}$ ) for $7 \mathrm{~h}$ to give the white paste, which was transferred into a reaction kettle and crystallized at $70{ }^{\circ} \mathrm{C}$ for 24 hours. After crystallization, a brown precipitate was formed and collected by centrifugation, and then washed three times with the water/ethanol mixture $(100 \mathrm{ml}$ for each wash, $\mathrm{v} / \mathrm{v}=4$. The collected samples were dried in an oven at $55^{\circ} \mathrm{C}$ overnight and ready for use.

Preparation of the composite coatings. Composite coatings were prepared of waterborne epoxy resin with fillers of STPP-LDHs (at various quantity, weight percentage, as shown in Table 1). After milling, the curing agent and deionized water were added into the mixture; then the mixture was stirred for another $20 \mathrm{~min}$ (at $120 \mathrm{ppm}$ by the magnetic stirrer) to give the final composite coating. In this work, the parent coating (i.e. the neat epoxy) and the composite coating with the LDHs filler were also prepared as the reference materials for comparison (Table 1).

To prepare the surface of the steel substrate (with rounded corners/edges), steel substrates were firstly polished by the fine emery paper, then washed with acetone and dried at $40{ }^{\circ} \mathrm{C}$ for further use. The prepared steel substrates were painted by a compressed air sprayer (using the samples in Table 1) and cured at room temperature. After the solidification treatment of the paint coated steel substrates, the thickness of the coating was measured by a Qnix 4500 digital meter, showing that the average coating thickness is $30 \pm 5 \mu \mathrm{m}$. The final coated specimens were kept in a desiccator for a week before any tests.

Table 1. Composite coating formulation with LDHs and STPP-LDHs.

\begin{tabular}{ccccc}
\hline Samples & Waterborne epoxy resin $(\mathrm{g})$ & Pigment $(\mathrm{g})$ & Curing agent $(\mathrm{g})$ & Deionized water $(\mathrm{g})$ \\
\hline Neat EP & 20 & - & 10 & 10 \\
LDHs(1.0\%)-EP & 20 & 0.2 & 10 & 10 \\
STPP-LDHs(0.5\%)-EP & 20 & 0.1 & 10 & 10 \\
STPP-LDHs(0.7\%)-EP & 20 & 0.14 & 10 & 10 \\
STPP-LDHs(1.0\%)-EP & 20 & 0.2 & 10 & 10 \\
STPP-LDHs(1.5\%)-EP & 20 & 0.4 & 10 & 10 \\
\hline
\end{tabular}

Characterization of materials. Fourier transform infrared spectroscopy was performed on Nicolet MNGNAIR560 instrument (Thermo Fisher Scientific, USA) with $4 \mathrm{~cm}^{-1}$ resolution. X-ray diffraction patterns were recorded on D/max-2500PC X-ray diffractometer (Rigaku, Japan), using $\mathrm{CuK} \alpha$ radiation at $50 \mathrm{kV}$ and $200 \mathrm{~mA}$ with a scanning rate of $1^{\circ} \mathrm{min}^{-1}$ by 0.01 steps. Thermalgravimetric analysis (TGA) was conducted under nitrogen $\left(\mathrm{N}_{2}\right)$ flow (heating rate $=10{ }^{\circ} \mathrm{C} \mathrm{min}^{-1}$ ) on a NETCH STA449C thermogravimetric analyzer (NETZSCH, Germany). The morphology of LDHs and STPP-LDHs was examined by scanning electron microscopy (SEM) using a JSM-6360LV SEM (JEOL, Japan).

Evaluation of anticorrosion performance of coatings. Electrochemical impedance spectroscopy (EIS) of coatings was performed using a Metrohm electrochemical workstation (Autolab 84362 with ZSimpwin software) to

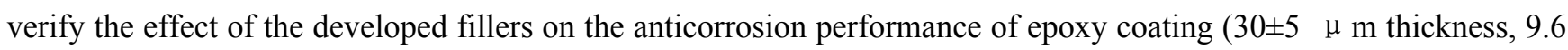
$\mathrm{cm}^{2}$ measurement area) on the mild steel substrate. The impedance measurement was carried out at room temperature 
in $3.5 \mathrm{wt} . \% \mathrm{NaCl}$ solution, and the experimental data were normalized with respect to $1 \mathrm{~cm}^{2}$. Under the open circuit potential, the test system consisted of a three-electrode cell, which was made up of a saturated calomel electrode (SCE, as the reference), a platinum electrode (as the counter) and a coated coupon (as the working electrode). Repeated measurements were conducted (at least three times) with the coatings used in this work, showing that the values were reproducible to better than $\pm 2 \%$. Impedance spectra of coupons after different immersion times were recorded in $10^{-2}$ to $10^{5} \mathrm{~Hz}$ frequency range, with the sinusoidal alternating potential signal of $10 \mathrm{mV}$.

The corrosion test of the coated specimens was also carried out by the neutral salt spray test. The condition used by the salt spray apparatus (YW $\alpha / \mathrm{Q}-150$ ) was according to the one specified by ASTM B117[31], i.e. continuous spraying with $5.0 \mathrm{wt} \% \mathrm{NaCl}$ solution at $35 \pm 2{ }^{\circ} \mathrm{C}$. The surface of the test specimens was inspected and the degree of rusting was rated by visual examination of the test specimens after $720 \mathrm{~h}$.

\section{Results and discussion}

Characterization of LDHs and STPP-LDHs. The synthesized LDHs and STPP-LDHs were characterized comparatively using various techniques. FTIR spectra of the samples are shown in Figure 1a, revealing that LDHs (red solid line in Figure 1a) have the characteristic IR fingerprints of MgAl hydrotalcites [32]. For STPP-LDHs (as the black solid line in Figure $1 \mathrm{~b} \underline{1 \mathrm{a}}$ ), in addition to the bands related to hydrotalcite (i.e. at 3445, 1636 and $668 \mathrm{~cm}^{-1}$, respectively), relevant bands associated with P-O vibrations were also identified. Specifically, they are (i) the antisymmetric stretching vibration of $\mathrm{P}-\mathrm{O}$ at around $1129 \mathrm{~cm}^{-1}$, (ii) the P-O symmetrical telescopic vibration at 1047 $\mathrm{cm}^{-1}$, (iii) the P-O-P asymmetric telescopic vibration at $920 \mathrm{~cm}^{-1}$ and (iv) the O-P-O deformation harmonic vibration at $569 \mathrm{~cm}^{-1}[33]$.
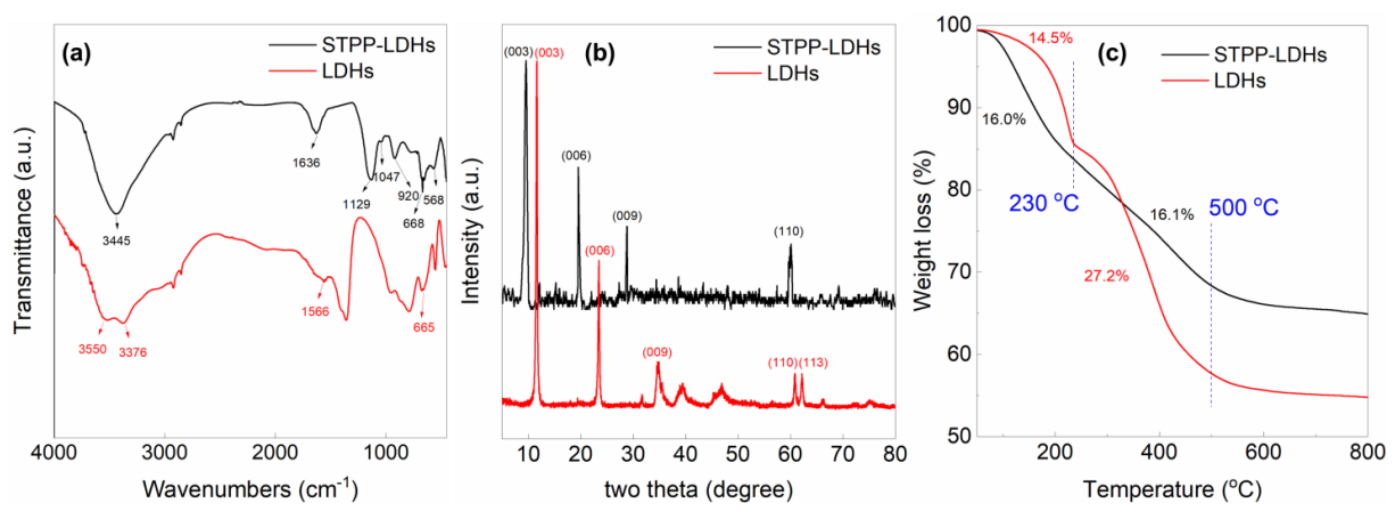

Figure 1 (a) FTIR spectra, (b) XRD patterns and (c) TGA of LDH and STPP-LDHs.

XRD analysis of LDHs and STPP-LDHs (Figure 1b) shows that (003), (006), (009) and (110) facets, i.e. the typical diffraction peaks of hydrotalcite, are present in both materials, suggesting that the intercalation of STPP in LDHs did not destroy the overall crystal structure of LDHs. The (003) planes represent the interlayers of hydrotalcite and the associated diffraction peak, interpreting the spacing of the interlayers [17]. After the intercalation of STPP, the position of (003) diffraction peak shifted from $11.60^{\circ}$ to $9.63^{\circ}$. According to the Bragg's law [34], the shift to the lower $2 \theta$ represents an increase in the interlayer spacing, specifically, from $0.762 \mathrm{~nm}$ for LDHs to $0.963 \mathrm{~nm}$ for STPPLDHs. Therefore, the intercalation of STPP ions in LDHs can improve the layered structure by increasing the interlayer spacing, and hence the porous structure of STPP-LDHs. In addition, the d spacing values of (003), (006) and (009) of STPP-LDHs correlate linearly, indicating that STPP-LDHs possess a more regular layered structure than LDHs.

The thermal decomposition behavior of LDHs and STPP-LDHs were analyzed by TGTGA, as displayed in Figure 1c. Both materials show the two-stage weight loss under the inert atmosphere $\left(\mathrm{N}_{2}\right)$. The first stage of weight loss 
terminates at about $230{ }^{\circ} \mathrm{C}$, which can be attributed to the rejection of the adsorbed water from the interlayers of these materials. LDHs and STPP-LDHs showed the comparable weight losses of 14.5\% (for LDHs) and 16.0\% (for STPPLDHs), indicating that LDHs and STPP-LDHs have the similar capacity of water adsorption. The second stage of weight loss from 230 to $500{ }^{\circ} \mathrm{C}$ was caused by condensation and dehydration of hydroxyl groups on the hydrotalcite laminates. It was found that the weight loss of STPP-LDHs (about 16.1\%) is less than that of LDHs (about 27.2\%), which indicates the occupation of interlayer space by the triphosphate ions after the intercalation, resulting in a reduced capacity of hydroxyl adsorption. After $500{ }^{\circ} \mathrm{C}$, the weight loss of the two substances was insignificant. The residual mass of STPP-LDHs (64.9\%) was greater than that of LDHs $(54.9 \%)$ which was owing to the inclusion of tripolyphosphate in STPP-LDHs.

SEM/EDS analysis was also performed (Figures 2 and 3). A SEM image of LDHs was presented in Figure 2a, it was shown that LDHs had the interlayer, and the porous structure, which was characteristic of hydrotalcite. As can be seen from figure $2 b$, STPP-LDHs possessed a more regular layered structure than LDHs(Figures 2a). This was primarily due to the presence of STTP ions. Similarly, the presence of element phosphorus in the STPP-LDHs sample was also illustrated in figure 3(EDS), and the content reaches $13.08 \mathrm{wt} \%$. In summary, based on the comparative characterization of LDHs and STPP-LDHs, one can confirm that $\mathrm{P}_{3} \mathrm{O}_{10}{ }^{5-}$ was successfully inserted into the interlayer of the hydrotalcite, forming STPP-LDHs.

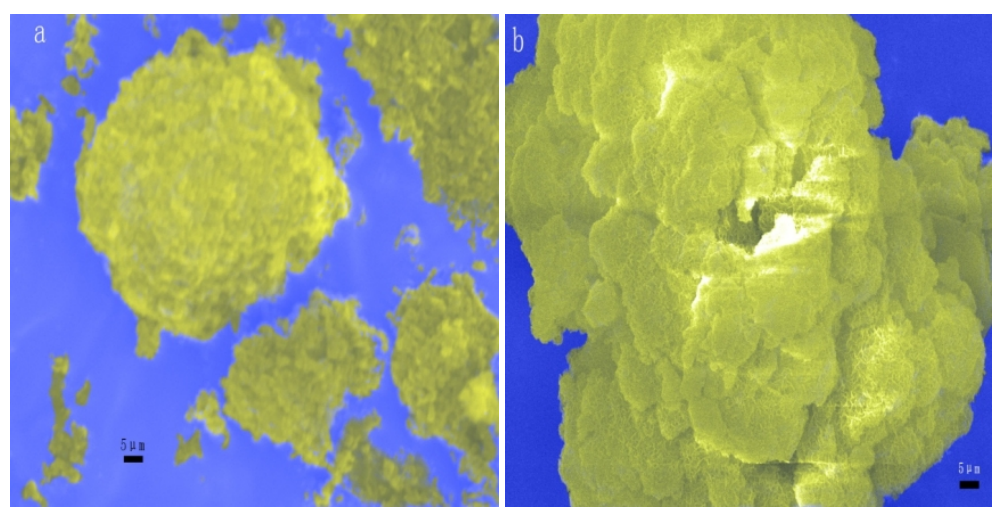

Figure 2 SEM images of the as-prepared (a) LDHs and (b) STPP-LDHs samples $(\times 10000)$.
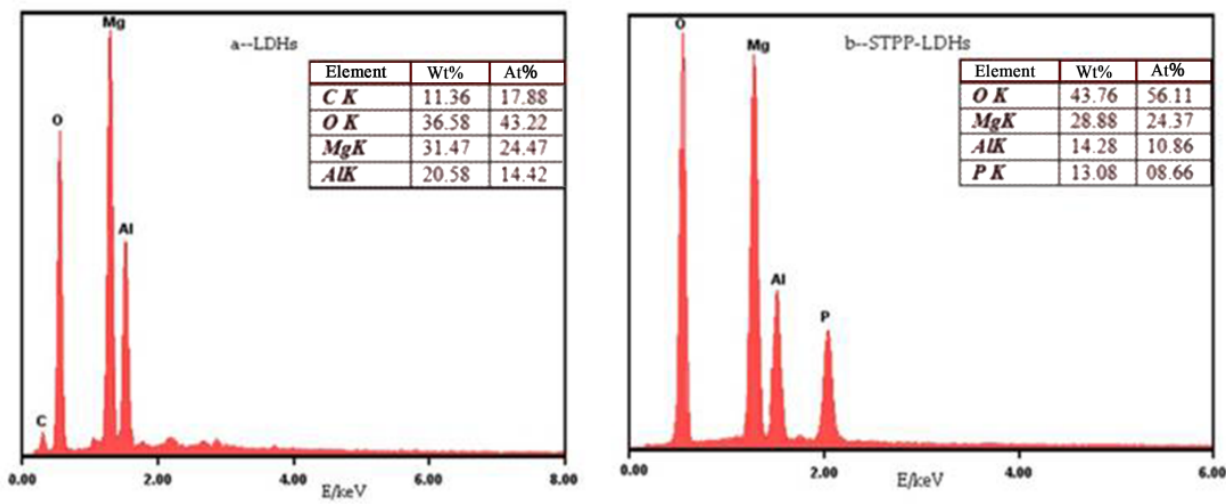

Figure 3 EDS analysis of the as-prepared (a) LDHs and (b) STPP-LDHs samples.

Corrosion testing of composite coatings using EIS. EIS measurements for the coated mild steel specimens were performed by immersing them in $3.5 \mathrm{wt} . \% \mathrm{NaCl}$ solution for a total $1,080 \mathrm{~h}$. The Nyquist plots were collected $0 \mathrm{~h}, 540$ $\mathrm{h}$ and $1,080 \mathrm{~h}$ after immersion, as exhibited in Figure 4, showing that the diameters of capacitance arcs are proportional to impedance modulus $[35,36]$.

Figure 4a shows Nyquist diagrams of various as-prepared coatings (i.e. immersion time $=0 \mathrm{~h}$ ). For neat EP coatings, their coating resistance at the low frequencies $(1 \sim 0.1 \mathrm{~Hz})$ was higher than $3.5 \times 10^{7} \Omega \cdot \mathrm{cm}^{2}$ (inset of Figure $4 \mathrm{a}$ ). 
After the $540 \mathrm{~h}$ immersion, the impedance value of neat EP decreased sharply, suggesting that the electrolyte solution can penetrated through the coating through the micropores (formed due to curing) and reach surface the interface of metal matrix. At this stage, the transport rate of electrolyte solution entering the coating layer via the micropores was much slower than the rate of electrolyte generating corrosion products at the coating/metal interface. Therefore, the process of corrosion was affected by the molecular diffusion of corrosion products into the solution. By further extending the immersion treatment to $1080 \mathrm{~h}$, the impedance of neat EP coating decreased again. At this stage, the electrolyte solution has penetrated the coating layer, hence the accelerated corrosion process due to charge transfer $[37,38]$. For the as-prepared LDHs(1.0\%)-EP coating, the measured capacitive semi-circles are much larger than that obtained for neat EP coating (Figure 4a), suggesting the improved barrier property of coatings [39] by modifying EP resin with $1 \mathrm{wt} . \%$ of LDH. By aging the $\mathrm{LDHs}(1.0 \%)$-EP coated specimen in $3.5 \mathrm{wt} . \% \mathrm{NaCl}$ solution, the impedance values of the LDHs(1.0\%)-EP decreased as well, but still being higher than that of neat EP resin, as shown in figures $4 \mathrm{~b}$ and $4 \mathrm{cFigs}, 4 \mathrm{~b}$ and $4 \mathrm{e}$. Therefore, it was proved that the addition of LDHs (1 wt.\%) could improve the barrier ability of EP resin coating effectively.

Coatings by STPP-LDHs-EP composites demonstrated the obviously improved barrier ability referencing to the neat EP and LDHs-EP coatings. Figure 4 shows that, under all conditions, the radius of capacitive semi-circle of the coating containing STPP-LDHs was much higher than the two control systems. These findings proved that the intercalation of tripolyphosphate ions with LDHs can effectively boost the anticorrosion ability of waterborne EP resin, as well as surpassing the LDHs modified EP resins [27]. Although the immersion corrosion test after long hours reduced the resistance value of all coatings inevitably (by comparing the data in Figures. $4 \mathrm{~b}$ and $4 \mathrm{c}$ to the data in Figure 4a), STPP-LDHs-EP coatings still showed the comparatively superior barrier abilities than the reference coatings. Among STPP-LDHs-EP coatings, STPP(1.0\%)-LDHs-EP was measured with the best resistance performance in all three tests.
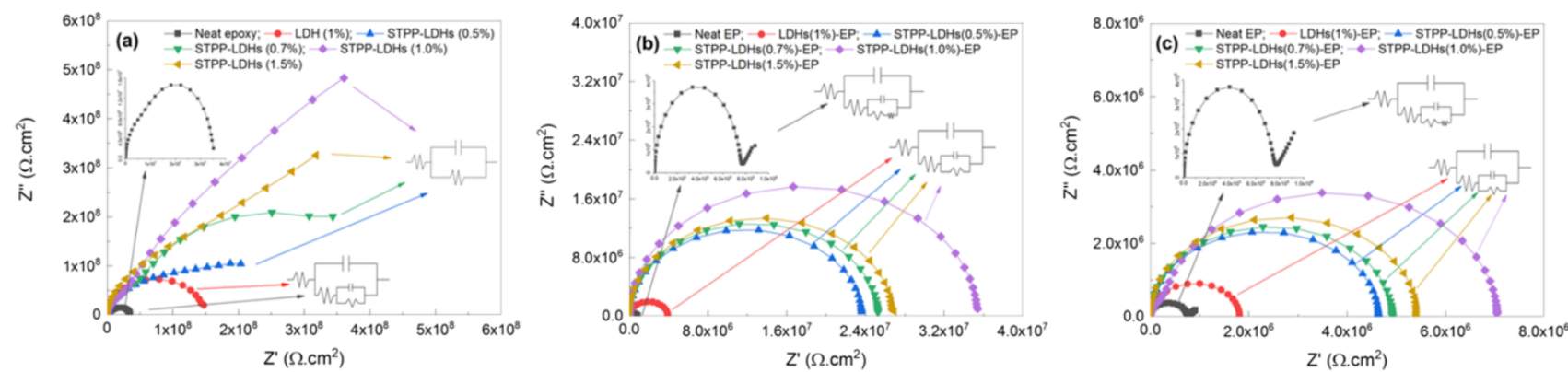

Figure 4 Nyquist diagrams of the six coatings at immersion times of (a) 0, (b) 540 and (c) $1080 \mathrm{~h}$ in $3.5 \mathrm{wt} \% \mathrm{NaCl}$ solution (insets: equivalent circuits and Nyquist diagrams for neat EP coatings).

Equivalent circuits:

$$
\begin{aligned}
& \text { Model 1: } \frac{1}{R_{p}}=\frac{1}{R_{1}} \\
& \text { Model 2: } \frac{1}{R_{p}}=\frac{1}{R_{1}+R_{2}} \\
& \text { Model 3: } \frac{1}{R_{p}}=\frac{1}{R_{1}+R_{2}}
\end{aligned}
$$

where $R_{p}$ represents the polarization resistance $R_{s}$ represents the solution resistance, $W$ represents the diffusion resistance, $R_{1}$ and $R_{2}$ represent the resistors in the circuits and $C_{x}$ represents the conductor in the circuits [40]. $W$ appears because the corrosive ions transports in the solution via diffusion in the process. 

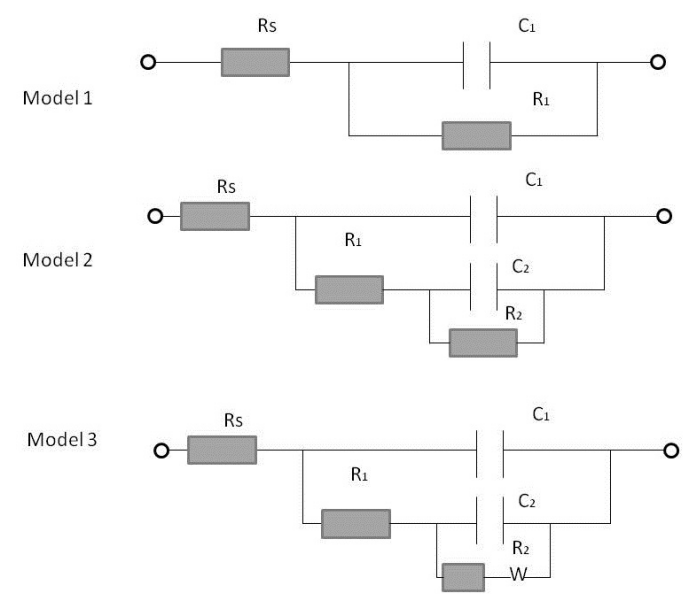

Figure 5 Equivalent electrical circuits proposed for the coatings.

Table 2. Parameter values obtained from the simulation circuit for the coatings immersed in $3.5 \mathrm{wt} . \% \mathrm{NaCl}$ solution up to $1080 \mathrm{~h}$.

\begin{tabular}{|c|c|c|c|c|c|c|c|c|}
\hline Samples & $\begin{array}{l}\text { Time } \\
\text { (h) }\end{array}$ & $\begin{array}{l}R_{s} \\
\left(\Omega \cdot \mathrm{cm}^{2}\right)\end{array}$ & $\begin{array}{l}R_{I} \\
\left(\Omega \cdot \mathrm{cm}^{2}\right)\end{array}$ & $\begin{array}{l}C_{l} \\
\left(\mathrm{~F} / \mathrm{cm}^{2}\right)\end{array}$ & $\begin{array}{l}R_{2} \\
\left(\Omega \cdot \mathrm{cm}^{2}\right)\end{array}$ & $\begin{array}{l}C_{2} \\
\left(\mathrm{~F} / \mathrm{cm}^{2}\right)\end{array}$ & $\begin{array}{l}W \\
\left(\Omega \cdot \mathrm{cm}^{2}\right)\end{array}$ & Model \\
\hline & 0 & 11.91 & $1.39 \times 10^{7}$ & $1.19 \times 10^{-9}$ & $4.42 \times 10^{7}$ & $9.8 \times 10^{-10}$ & - & 2 \\
\hline & 540 & 12.68 & $7.62 \times 10^{5}$ & $1.55 \times 10^{-9}$ & $2.76 \times 10^{6}$ & $2.12 \times 10^{-9}$ & $9.41 \times 10^{-7}$ & 3 \\
\hline \multirow{2}{*}{ EP } & 1080 & 12.35 & $5.36 \times 10^{5}$ & $1.77 \times 10^{-9}$ & $1.05 \times 10^{5}$ & $2.12 \times 10^{-9}$ & $9.41 \times 10^{-8}$ & 3 \\
\hline & 0 & 14.49 & $3.91 \times 10^{7}$ & $7.94 \times 10^{-10}$ & $6.81 \times 10^{7}$ & $3.29 \times 10^{-10}$ & - & 2 \\
\hline \multirow[t]{2}{*}{ LDHs(1.0\%)-EP } & 540 & 10.00 & $3.93 \times 10^{6}$ & $7.25 \times 10^{-10}$ & $1.14 \times 10^{7}$ & $9.75 \times 10^{-9}$ & - & 2 \\
\hline & 1080 & 10.72 & $1.81 \times 10^{6}$ & $5.67 \times 10^{-10}$ & $2.69 \times 10^{6}$ & $4.37 \times 10^{-10}$ & - & 2 \\
\hline \multirow{2}{*}{ STPP-LDHs(0.5\%)- } & 0 & 14.07 & $1.91 \times 10^{8}$ & $7.77 \times 10^{-10}$ & - & - & - & 1 \\
\hline & 540 & 10.79 & $2.36 \times 10^{7}$ & $5.13 \times 10^{-10}$ & $3.48 \times 10^{7}$ & $2.58 \times 10^{-10}$ & - & 2 \\
\hline EP & 1080 & 10.84 & $4.63 \times 10^{6}$ & $5.65 \times 10^{-10}$ & $1.00 \times 10^{6}$ & $5.13 \times 10^{-10}$ & - & 2 \\
\hline \multirow{2}{*}{ STPP-LDHs(0.7\%)- } & 0 & 12.35 & $3.42 \times 10^{8}$ & $7.91 \times 10^{-10}$ & - & - & - & 1 \\
\hline & 540 & 10.71 & $2.53 \times 10^{7}$ & $4.21 \times 10^{-10}$ & $3.91 \times 10^{7}$ & $4.51 \times 10^{-11}$ & - & 2 \\
\hline EP & 1080 & 10.72 & $4.91 \times 10^{6}$ & $5.06 \times 10^{-10}$ & $1.01 \times 10^{6}$ & $6.22 \times 10^{-10}$ & - & 2 \\
\hline \multirow{2}{*}{ STPP-LDHs(1.0\%)- } & 0 & 11.20 & $6.01 \times 10^{8}$ & $4.85 \times 10^{-10}$ & - & - & - & 1 \\
\hline & 540 & 10.77 & $3.54 \times 10^{7}$ & $1.22 \times 10^{-10}$ & $4.16 \times 10^{7}$ & $9.75 \times 10^{-9}$ & - & 2 \\
\hline EP & 1080 & 11.34 & $3.89 \times 10^{6}$ & $1.11 \times 10^{-10}$ & $6.04 \times 10^{6}$ & $1.69 \times 10^{-11}$ & - & 2 \\
\hline \multirow{2}{*}{ STPP-LDHs(1.5\%)- } & 0 & 16.94 & $4.23 \times 10^{8}$ & $6.73 \times 10^{-10}$ & - & - & - & 1 \\
\hline & 540 & 13.45 & $1.62 \times 10^{7}$ & $1.01 \times 10^{-10}$ & $1.06 \times 10^{7}$ & $3.60 \times 10^{-10}$ & - & 2 \\
\hline EP & 1080 & 12.23 & $5.42 \times 10^{6}$ & $1.73 \times 10^{-9}$ & $2.13 \times 10^{6}$ & $7.01 \times 10^{-10}$ & - & 2 \\
\hline
\end{tabular}

To quantify the corrosion resistance of samples under study from the immersion tests, we built three equivalent circuits to fit EIS data (Figure 5) [41] and the fitted results are shown in Table 2. since different models were used to fit different scenarios, it is not possible to compare the fitted results directly. Therefore, the polarization resistance (Rp), which is defined as the difference between the real impedance of the Nyquist plot at zero frequency and the solution resistance,[42] was calculated for comparison. The calculated polarization resistance of samples under study at immersion times of $0,540,1080 \mathrm{~h}$ (in $3.5 \mathrm{wt} . \% \mathrm{NaCl}$ solution) is presented in Figure 6. Initially, STPP-LDHs(1.0\%)EP coating showed the largest value of Rp of $6.009 \times 10^{8} \Omega \cdot \mathrm{cm}^{2}$, whereas Rp values of the neat EP and LDHs(1.0\%)- 
EP coatings were relatively low, i.e. $4.425 \times 10^{7}$ and $1.071 \times 10^{8} \Omega \cdot \mathrm{cm}^{2}$, respectively. By immersing the coated specimens in $\mathrm{NaCl}$ solution for $540 \mathrm{~h}$ and $1080 \mathrm{~h}$, this trend was still true. The polarization resistance of all samples decreased after the immersion corrosion test, but STPP-LDHs-EP coatings still showed better anticorrosive property than the neat EP and LDHs(1.0\%)-EP. For example, after $540 \mathrm{~h}$ immersion, STPP-LDHs-EP coatings have Rp values centered at $6.432 \times 10^{7} \Omega \cdot \mathrm{cm}^{2}$ (standard deviation $=8.846 \times 10^{6} \Omega \cdot \mathrm{cm}^{2}$ ), higher than $3.524 \times 10^{6} \Omega \cdot \mathrm{cm}^{2}$ for neat EP and $1.531 \times 10^{7} \Omega \cdot \mathrm{cm}^{2}$ for LDHs(1.0\%)-EP. Therefore, the findings so far confirm that (i) the lamellar structure of LDHs can increase the barrier property of epoxy coating and improve the anticorrosive property of coating, 14 about seven folds after $1080 \mathrm{~h}$ immersion test (ii) the intercalation of tripolyphosphate in LDHs can enhance the anticorrosive performance of LDHs in coatings, about 12 folds after $1080 \mathrm{~h}$ immersion.

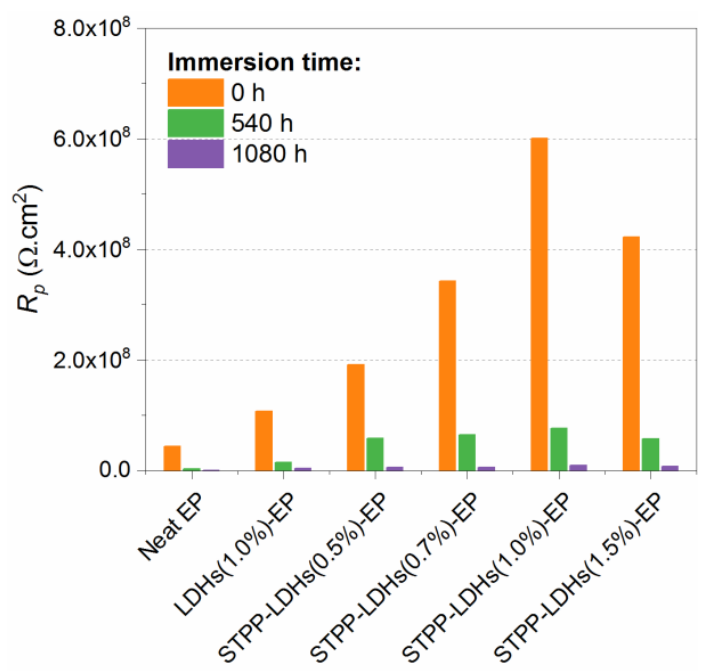

Figure 6 Polarization resistance of the six coatings at immersion times of $0,540,1080 \mathrm{~h}$ in $3.5 \mathrm{wt} \% \mathrm{NaCl}$ solution.

Bode plots of EIS data are shown in Figure 7. By adding fillers (LDHs or STPP-LDHs) into the coating, the corrosion resistance of coatings was improved, as shown in Figure 7a. The impedance $(|\mathrm{Z}|)$ value of the coating at a certain frequency is the indicator of the difficulty of ions traveling through the coating, i.e. the higher of (|Z|) value, the more difficult for ions to travel, and hence the better corrosion resistance of the coating [43]. For the as prepared samples, over the frequency range studied, the value of impedance $(|Z|)$ of the neat coating is smaller than that of other coatings, indicating that LDHs and STPP-LDHs played a role in impeding the diffusion of corrosive ions through the coating to the metal surface. During the immersion corrosion test (Figures. $7 \mathrm{~b}$ and $7 \mathrm{c}$ ), the impedance value of neat EP and LDHs(1.0\%)-EP coatings decreased evidently, especially at the low frequencies $(<10 \mathrm{~Hz})$, e.g. for neat epoxy coating from about $3.5 \times 10^{7} \Omega \cdot \mathrm{cm}^{2}$ to $8.6 \times 10^{5} \Omega \cdot \mathrm{cm}^{2}$ after $540 \mathrm{~h}$ of immersion. Clearly, the presence of STPP-LDHs fillers in the epoxy coating can improve the interfacial barrier of the composites, confirming the effectiveness of intercalating tripolyphosphate into LDHs to improve the corrosion resistance of the coating. It was also found that the amount of STPP-LDHs in the coating influences the. For the samples under study, the EP coating containing $1.0 \mathrm{wt} \%$ STPP-LDHs showed the best anticorrosion performance highest over the entire frequency range. 

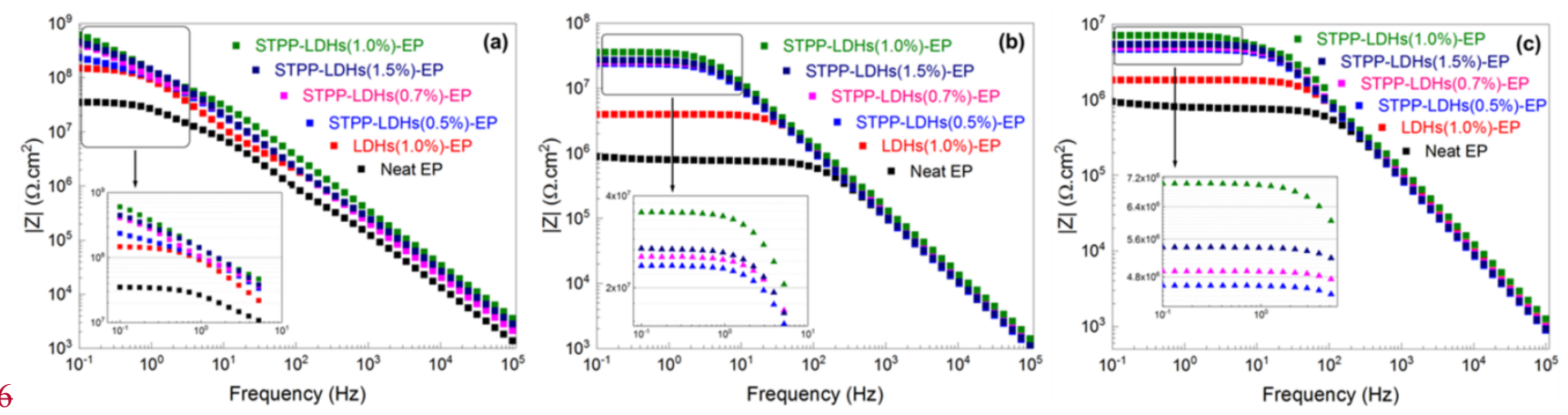

Figure 7 Bode plots of the coatings at immersion times of (a) 0, (b) 540 and (c) $1080 \mathrm{~h}$ in $3.5 \mathrm{wt} \% \mathrm{NaCl}$ solution.

Salt Spray Test. The relative corrosion-resistance information of the coated mild steel specimens (without artificial defects) was obtained by the salt spray test. After $720 \mathrm{~h}$ exposure to a controlled corrosive environment in the salt fog chamber (i.e. $5.0 \mathrm{wt} \% \mathrm{NaCl}$ solution at $35 \pm 2{ }^{\circ} \mathrm{C}$ ), the specimens were studied visually by comparing their optical images, as shown in Figure 8. We find that the specimen with neat epoxy resin coating was prone to corrosion and rusting in the salt spray test, leading to considerable rust formation, as shown in Figure 8a. The addition of layered materials into the epoxy resin paint coating can improve the anticorrosion ability of epoxy coatings. In comparison to the specimen coated with neat epoxy resin, the formation of rusty product on LDHs(1.0\%)-EP coated specimen was suppressed, but the cloud rust spots were still formed due to pitting. Conversely, the specimens with STPP-LDHs modified epoxy coatings developed insignificant rusting after $720 \mathrm{~h}$ test. The effectiveness of triphosphate-intercalated LDHs to enhance the corrosion-resistance of the epoxy coating under study. The results demonstrate that the addition of STPP-LDHs in epoxy resin coating, especially STPP-LDHs(1.0\%)-EP, could effectively suppress the occurrence and propagation of localized corrosion under a harsh controlled corrosive condition, which was consistent with the findings by EIS analysis. Generally, the anticorrosion performance of coatings can be improved by increasing the amount of anticorrosive fillers. However, the presence of too many fillers in the coating can also cause bulge particle defects due to the agglomeration of fillers (as shown in Figure 8f), deteriorating the anticorrosive performance.

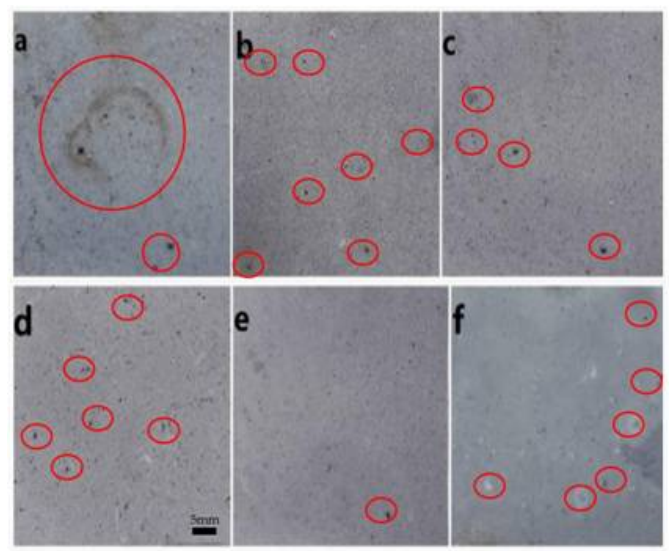

Figure 8 Surface morphology of the coatings after the salt spray test for $600 \mathrm{~h}$ : (a) neat EP; (b) LDHs(1\%)-EP; (c) STPP-LDHs(0.5\%)-EP; (d) STPP-LDHs(0.7\%)-EP; (e) STPP-LDHs(1.0\%)-EP; and (f) STPP-LDHs(1.5\%)-EP.

Based on the results obtained, the anti-corrosion mechanism of STPP-LDHs fillers in the EP coating layer was suggested, as illustrated in scheme 1. Firstly, the presence of LDHs layered structure hinders the diffusion of corrosion ions through the coating layer and stops corrosion ions from reaching the metal substrate immediately [44]. Secondly, triphosphate ions in STPP-LDHs can exchange with corrosive ions such as $\mathrm{Cl}^{-}$to trap them in the interlayers of LDHs, 
reducing the amount of ions in the coating layer for metal corrosion $[13,15,45,46]$. Finally, the released tripolyphosphate ion can act as the chelating agent, initiating the passivation of the metal surface via complexation which makes metals avoid erosion by corrosion ions $[28,47,48]$. The mechanism explains the improved corrosion resistance of STPP-LDHs-EP coatings in reference to neat EP and LDHs-EP coatings, as evidenced by the coating corrosion resistance test.

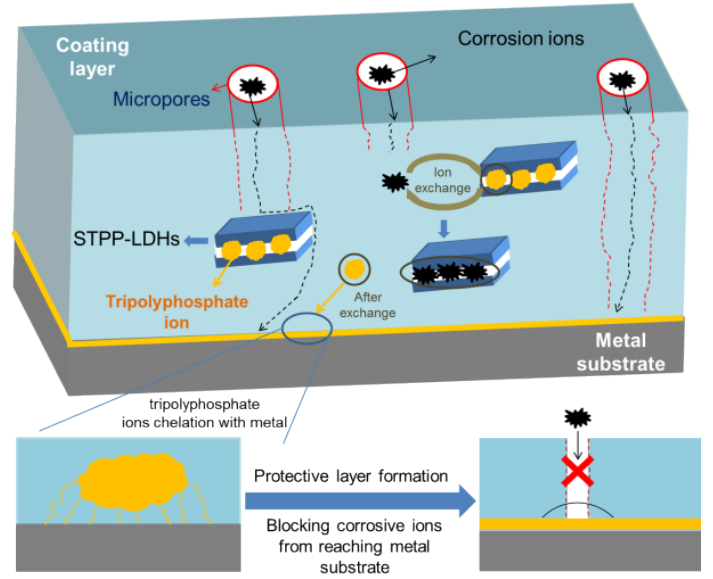

Scheme 1 Schematic diagram of the anti-corrosion mechanism by STPP-LDHs in EP coatings.

\section{Conclusions}

The anticorrosion ability of the waterborne epoxy (EP) coating can be improved by adding layered double hydroxides (LDHs) fillers. In this work, we demonstrated that (i) the modification of LDHs with tripolyphosphate ions (via the intercalation of sodium tripolyphosphate, STPP, into the layered structures of LDHs) is possible, giving STPP-LDHs and (ii) STPP-LDHs are good candidates to prepare EP based coatings with excellent anticorrosion performance. The successful intercalation of STPP with MgAl-LDHs was confirmed by FTIR, XRD, TGA and SEM characterization. STPP-LDHs modified EP coatings (i.e. STPP-LDHs-EP coatings) were prepared with different weigh percentages of the fillers (i.e. from 0.5 to $1.5 \mathrm{wt} . \%$ ) and used subsequently for coating the mild steel samples for the corrosion tests under the controlled environment. Compared with the EP and LDHs(1.0\%)-EP coated specimens, STPP-LDHs-EP coatings showed the significantly improved the corrosion resistance in the environment containing $\mathrm{NaCl}$ solutions, evidenced by the EIS (with $3.5 \mathrm{wt} \% \mathrm{NaCl}$ solution) and salt spray test (with $5.0 \mathrm{wt} \% \mathrm{NaCl}$ solution). Among the coatings under study, STPP-LDHs(1.0\%)-EP was proved to have the best barrier property for anti-corrosion applications.

Acknowledgments: NW gratefully acknowledges the financial support for her research group by the Top Talents of Liaoning Province (Grant No.[2016]864); Innovative Talents Program of Universities in Liaoning Province (Grant No.[2017]053); Technological Innovation Talents Program for Youngs and Middles of Shenyang, Shenyang Municipal Science and Technology Bureau (Grant No: RC170118) and Sino-Spanish Advanced Materials Institute, Shenyang Municipal Science and Technology Bureau (Grant No:18-005-6-04). XF thanks the partial support by The Royal 442Society International Exchange Award (IE161344) to enable the collaboration.

\section{Compliance with ethical standards}

Conflict of interest The authors declare that they have no conflict of interest.

\section{Reference}

[1] D. Liu, W.J. Zhao, S. Liu, Q.H. Cen, Q.J. Xue, Comparative tribological and corrosion resistance properties of epoxy composite coatings reinforced with functionalized fullerene C60 and grapheme, Surf. Coat. Tech 286 (2016) 354-364. http://doi.org/ 10.1016/j.surfcoat.2015.12.056. 
[2] N. Wang, Y.N. Zhang, J.S. Chen, J. Zhang, Q.H. Fang, Dopamine modified metal-organic frameworks on anticorrosion properties of waterborne epoxy coatings, Prog. Org. Coat 109 (2017) 126-134. http://doi.org/10.1016/j.porgcoat.2017.04.024.

[3] Erdmenger T, Guerrero-Sanchez C, Vitz J, Hoogenboom R, Schubert US, Recent developments in the utilization of green solvents in polymer chemistry, Chem. Soc. Rev 39 (2010) 3317-3333.http://doi.org/10.1039/b909964f.

[4] N. Wang, W.L. Fu, J. Zhang, Corrosion performance of waterborne epoxy coatings containing polyethylenimine treated mesoporous- $\mathrm{TiO}_{2}$, nanoparticles on mild steel, Prog. Org. Coat 89 (2015) 114-122. http://doi.org/10.1016/j.porgcoat.2015.07.009.

[5] W.G. Ji, J.M. Hu, L. Liu, J.Q. Zhang, C.N. Cao, Water uptake of epoxy coatings modified with $\gamma$-APS silane monomer, Prog. Org. Coat 57 (2006) 439-443. http://doi.org/10.1016/j.porgcoat.2006.09.025.

[6] L. Guadagno, L. Vertuccio, A. Sorrentino, M. Raimondo, C. Naddeo, V. Vittoria, G. Iannuzzo, E. Calvi, et. al, Mechanical and barrier properties of epoxy resin filled with multi-walled carbon nanotubes, Carbon 47(2009) 2419-2430. http://doi.org/10.1016/j.carbon.2009.04.035.

[7] T.P. Mohan, M.R. Kumar, R. Velmurugan, Mechanical and barrier properties of epoxy polymer filled with nanolayered silicate clay particles, J. Mater. Sci 41(2006) 2929-2937. http://doi.org/10.1007/s10853-006-5164-4.

[8] M. Nematollahi, M. Heidarian, M. Peikari, S.M. Kassiriha, N. Arianpouya, M.M. Esmaeilpour, Comparison between the effect of nanoglass flake and montmorillonite organoclay on corrosion performance of epoxy coating, Corros. Sci 52 (2010) 1809-1817. http://doi.org/10.1016/j.corsci.2010.01.024.

[9] N. Wang, K.Q. Cheng, H. Wu, C. Wang, Q.C. Wang, H.F. Wang, Effect of nano-sized mesoporous silica MCM41 and MMT on corrosion properties of epoxy coating, Prog. Org. Coat 75 (2012) 386-391. http://doi.org/10.1016/j.porgcoat.2012.07.009.

[10] N. Wang, Y.H. Wu, K.Q. Cheng, J. Zhang, Investigation on anticorrosion performance of polyanilinemesoporous MCM-41 composites in new water-based epoxy coating, Mater. Corro, 65(10) (2014) 968-976. http://doi.org/10.1002/maco.201307458.

[11] N. Wang, H.Y. Gao, J. Zhang, P. Kang, Effect of graphene oxide/ZSM-5 hybrid on corrosion resistance of waterborne epoxy coating, Coatings 8(5) (2018) 179. http://doi.org/10.3390/coatings8050179.

[12] U. Costantino, V. Ambrogi, M. Nocchetti, Hydrotalcite-like compounds: Versatile layered hosts of molecular anions with biological activity, Micropor. Mesopor. Mat 107 (2008) 149-160. http://doi.org/10.1016/j.micromeso.2007.02.005.

[13] S.K. Poznyak, J. Tedim, L.M. Rodrigues, A.N. Salak, M.L. Zheludkevich, L.F. Dick, M.G. Ferreira, Novel inorganic host layered double hydroxides intercalated with guest organic inhibitors for anticorrosion applications, ACS Appl. Mater. Interfaces 1 (2009) 2353-2362. http://doi.org/10.1021/am900495r.

[14] F.L. Theiss, S.J. Couperthwaite, G.A. Ayoko, L.F. Ray, A review of the removal of anions and oxyanions of the halogen elements from aqueous solution by layered double hydroxides, J. Colloid. Interf. Sci 417 (2014) 356-368. http://doi.org/10.1016/j.jcis.2013.11.040.

[15] J.M. Vega, N. Granizo, D.D.L. Fuente, J. Simancas, M. Morcillo, Corrosion inhibition of aluminum by coatings formulated with Al-Zn-vanadate hydrotalcite, Prog. Org. Coat 70 (2011) 213-219. http://doi.org/10.1016/j.porgcoat.2010.08.014.

[16] R.G. Buchheit, H. Guan, S. Mahajanam, F. Wong, Active corrosion protection and corrosion sensing in chromate-free organic coatings, Prog. Org. Coat 47(3-4) (2003) 174-182. http://doi.org/10.1016/j.porgcoat.2003.08.003. 
[17] V. Shkirskiy, P. Keil, H. Hintzebruening, F. Leroux, P. Vialat, G. Lefèvre, K. Ogle, Factors affecting $\mathrm{moO}_{4}{ }^{2-}$ inhibitor release from $\mathrm{Zn}_{2} \mathrm{Al}$ based layered double hydroxide and their implication in protecting hot dip galvanized steel by means of organic coatings, Acs Appl Mater Interfaces, 7(45) (2015) 25180-25192. http://doi.org/10.1021/acsami.5b06702.

[18] T. Stimpfling, F. Leroux, H. Hintze-Bruening, Organo-modified layered double hydroxide in coating formulation to protect AA2024 from corrosion, Colloid. Surface. A 458 (2014) 147-154. http://doi.org/10.1016/j.colsurfa.2014.01.042.

[19] S.K. Poznyak , J. Tedim, L.M. Rodrigues, A.N. Salak, M.L. Zheludkevich, L.F. Dick, M.G. Ferreira, Novel inorganic host layered double hydroxides intercalated with guest organic inhibitors for anticorrosion applications, ACS Appl. Mater. Interfaces 1 (2009) 2353-2362. http://doi.org/10.1021/am900495r.

[20] J. Tedim, S.K. Poznyak, A. Kuznetsova, D. Rap, T. Hack, M.L. Zheludkevich, M.G.S. Ferreira, Enhancement of Active Corrosion Protection via Combination of Inhibitor-Loaded Nanocontainers, ACS Appl. Mater. Interfaces 2(5) (2010) 1528. http://doi.org/10.1021/am100174t.

[21] M.L. Zheludkevich, S.K. Poznyak, L.M. Rodrigues, D. Raps, T. Hack, L.F. Dick, T. Nunesd, M.G.S. Ferreira, Active protection coatings with layered double hydroxide nanocontainers of corrosion inhibitor, Corros. Sci 2010, 52(2) (2010) 602-611. http://doi.org/10.1016/j.corsci.2009.10.020.

[22] T.T.X. Hang, T.A. Truc, N.T. Duong, Nadine Pébère, M.G. Olivier, Layered double hydroxides as containers of inhibitors in organic coatings for corrosion protection of carbon stee, Prog. Org. Coat 74(2) (2012) 343-348. http://doi.org/10.1016/j.porgcoat.2011.10.020.

[23] T. Stimpfling, F. Leroux, Hintze-Bruening, Horst, Phosphate - Based Organic Molecules Interleaved with Layered Double Hydroxide: Unraveling the Roles of Host Cations and the Guest - Inhibiting Effect in Aluminum Corrosion Protection, Eur. J. Imorg. Chem 2012(32) (2015) 5396-5404. http://doi.org/10.1002/ejic.201200504.

[24] V.F. Vetere, M.C. Deyá, R. Romagnoli, B.D. Amo, Calcium tripolyphosphate: An anticorrosive pigment for paint, J. Coating. Technol 73 (2001): 57-63. http://doi.org/10.1007/BF02698398.

[25] Mohammadi S, Shariatpanahi H, Taromi FA, Neshati J, Electrochemical and anticorrosion behaviors of hybrid functionalized graphite nano-platelets/tripolyphosphate in epoxy-coated carbon steel, Mater. Res. Bull 80(2016):7-22. http://doi.org/10.1016/j.materresbull.2015.06.052.

[26] Blustein G, Deyá MC, Romagnoli R, Amo BD, Three generations of inorganic phosphates in solvent and waterborne paints: A synergism case, Appl. Surf. Sci 252(2005):1386-1397. http://doi.org/10.1016/j.apsusc.2005.02.096.

[27] Deyá MC, Sarli ARD, Amo BD, Romagnoli R, Performance of Anticorrosive Coatings Containing Tripolyphosphates in Aggressive Environments, Ind. Eng. Chem. Res 47(2008):7038-7047. http://doi.org/10.1021/ie071544d.

[28] Xu WZ, Xu BL, Li AJ, Wang XL, Wang GS, The Flame Retardancy and Smoke Suppression of MgAl Layered Double Hydroxides Containing P and Si in Polyurethane Elastomer, Ind. Eng. Chem. Res 55(2016):11175-11185. http://doi.org/10.1016/j.compositesa.2016.09.013.

[29] Xu W, Wang S, Li A, Synthesis of aminopropyltriethoxysilane grafted/tripolyphosphate intercalated ZnAl LDHs and its performance in the flame retardancy and smoke suppression of polyurethane elastomer, Rsc. Adv 6(2016):48189-48198.http://doi.org/ 10.1039/C6RA06713A.

[30] Xing K, Wang H, Guo L, Adsorption of tripolyphosphate from aqueous solution by $\mathrm{Mg}-\mathrm{Al}-\mathrm{CO}_{3}$-layered double 
hydroxides, Colloid. Surface. A 328(2008):15-20. http://doi.org/10.1016/j.colsurfa.2008.06.015.

[31] ASTM B117-03 Standard Practice for Operating Salt Spray (Fog) Apparatus, ASTM. International 2003. https://www.astm.org/DATABASE.CART/HISTORICAL/B117-03.htm.

[32] Dong YM, Zhu YG, Dai X, Zhao D, Zhou X, Qi Y, Koo JH, Ammonium alcohol polyvinyl phosphate intercalated LDHs/epoxy nanocomposites, J. Therm. Anal. Calorim 122(2015):135-144. http://doi.org/10.1007/s10973-015-4718-6.

[33] Zhang QL, Wu QX, Lin DQ, Yao SJ, Effect and mechanism of sodium chloride on the formation of chitosancellulose sulfate-tripolyphosphate crosslinked beads, Soft. Matter 9(2013):10354-10363. http://doi.org/10.1039/c3sm52051j.

[34] Bragg WH, Bragg WL, The reflection of X-rays by crystals, Proc. R. Soc. Lond. A 88(1913):428-438. http://doi.org/10.1098/rspa.1913.0082.

[35] Zhang JT, Hu JM, Zhang JQ, Cao CN, Studies of water transport behavior and impedance models of epoxycoated metals in $\mathrm{NaCl}$ solution by EIS, Prog. Org. Coat 51(2004):145-151. http://doi.org/10.1016/j.porgcoat.2004.08.001.

[36] Shinde VP, Study of water transport characteristics of poly(o-ethylaniline) coatings: Corrosion mechanism, Ionics 24(2018):605-615. http://doi.org/10.1007/s11581-017-2213-8.

[37] Chen Y, Hong T, Gopal M, Epson WPJ, EIS studies of a corrosion inhibitor behavior under multiphase flow conditions, Corros. Sci 42(2000):979-990. http://doi.org/10.1016/S0010-938X(99)00127-4.

[38] Yang XK, Li Q, Zhang SY, Gao H, Luo F, Dai Y, Electrochemical corrosion behaviors and protective properties of $\mathrm{Ni}-\mathrm{Co}-\mathrm{TiO}_{2}$ composite coating prepared on sintered NdFeB magnet, J. Solid. State. Electr 14(2010):16011608. http://doi.org/10.1002/maco.200905449.

[39] Scully JR, Electrochemical Impedance of Organic-Coated Steel: Correlation of Impedance Parameters with Long-Term Coating Deterioration, J. Electrochem. Soc 136(1989):979-990. http://doi.org/10.1149/1.2096897.

[40] Zhang, Y; Yu, PH; Wu, JJ, Chen F, Li YD, Zhang YL, Zuo Y, Oi YGL, Enhancement of anticorrosion protection via inhibitor-loaded ZnAlCe-LDH nanocontainers embedded in sol-gel coatings. Journal of Coatings Technology \& Research 15(2018): 303-313. http://doi.org/10.1007/s11998-017-9978-6.

[41] Liu CB, Du P, Zhao HC, Wang LP, Synthesis of L-histidine-attached graphene nanomaterials and their application for steel protection, ACS Appl. Nano. Mater 1(2018):1385-1395. http://doi.org/10.1021/acsanm.8b00149.

[42] Fan F, Zhou CY, Wang X, Szpunar J, Layer-by-Layer Assembly of a Self-Healing Anticorrosion Coating on Magnesium Alloys, ACS Appl. Mater. Interfaces 7(2015):27271-27278. http://doi.org/10.1021/acsami.5b08577.

[43] Wang N, Diao XL, Zhang J, Kang P, Corrosion Resistance of Waterborne Epoxy Coatings by Incorporation of Dopamine Treated Mesoporous- $\mathrm{TiO}_{2}$ Particles, Coatings 8(2018):209. http://doi.org/10.3390/coatings8060209.

[44] Yu D, Wen S, Yang J, RGO modified ZnAl-LDH as epoxy nanostructure filler: A novel synthetic approach to anticorrosive waterborne coating, Surf. Coat. Tech 326(2017):207-215. http://doi.org/10.1016/j.surfcoat.2017.07.053.

[45] Tedim J, Poznyak SK, Kuznetsova A, Raps D, Hack T, Zheludkevich ML, Ferreira MGS, Enhancement of Active Corrosion Protection via Combination of Inhibitor-Loaded Nanocontainers, ACS Appl. Mater. Interfaces 2(2010):1528. http://doi.org/10.1021/am100174t.

[46] Peng F, Li H, Wang D, Tian P, Tian Y, Yuan G, Enhanced Corrosion Resistance and Biocompatibility of Magnesium Alloy by Mg-Al-Layered Double Hydroxide, ACS Appl. Mater. Interfaces 8(2016):35033-35044. 
http://doi.org/10.1021/acsami.6b12974.

[47] Deyá MC, Vetere VF, Romagnoli R, Amo BD, Zinc tripolyphosphate: An anticorrosive pigment for paints, Surf. Coat. Int. Pt. B-C 86(2003):79-85. http://doi.org/10.1007/BF02699598.

[48] Vetere VF, Deyá MC, Romagnoli R, Amo BD, Calcium tripolyphosphate: An anticorrosive pigment for paint, J. Coating. Technol 73(2001):57-63. http://doi.org/10.1007/BF02698398. 